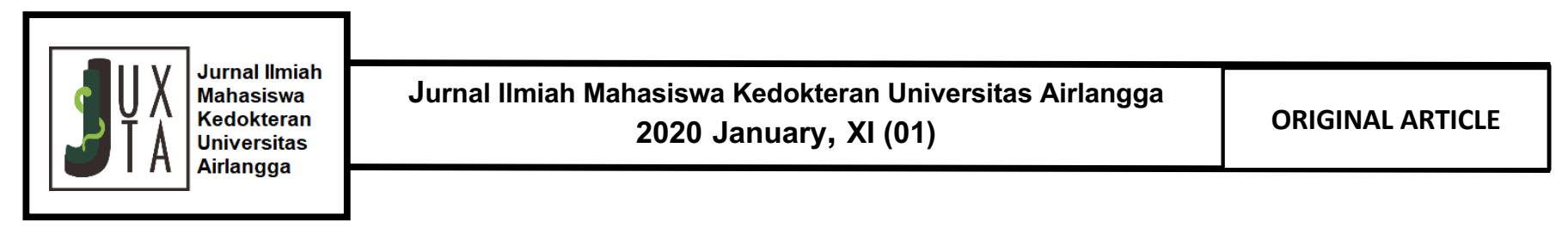

\title{
Bone Tuberculosis: Clinical Profile of 40 Patients in Dr. Soetomo General Hospital Surabaya
}

\section{Yonatan Esli Alexander Tidja ${ }^{1}$, Sjahjenny Mustokoweni ${ }^{2^{\star}}$, Tania Ardiani Saleh $^{3}$}

${ }^{1}$ Faculty of Medicine, Universitas Airlangga, Surabaya, Indonesia.

${ }^{2}$ Department of Pathological Anatomy, Faculty of Medicine, Universitas Airlangga, Surabaya, Indonesia. ${ }^{3}$ Department of Anatomy and Histology, Faculty of Medicine, Universitas Airlangga, Surabaya, Indonesia.

\section{A B S T R A C T}

Introduction: Bone and joint tuberculosis are specific infection inflammation of Mycobacterium tuberculosis, mostly affected bone and joint confirmed by acceleration of vascular supply to vertebrae and growth line of long bone. The aim of this study is to know clinical profile of bone and joint tuberculosis' patients.

Methods: This study was conducted using descriptive observational method, samples were tested by observation descriptive test.

Results: The average ages of bone and joint tuberculosis hospitalized patients of RSUD Dr. Soetomo Surabaya are 35-44 years. There are 22 cases on male $(55 \%)$ and 18 cases on female (45\%) with 29 subjects of Hb's abnormal number $(72.5 \%)$, 15 subjects of abnormal leucocytes (37.5\%), 20 subjects of abnormal thrombocyte (50\%), 34 subjects of abnormal ESR (94.4\%), 20 patients of abnormal C-reactive protein $(54.1 \%), 11$ subjects of abnormal serum creatinine $(28.9 \%), 13$ subjects of abnormal sodium level (35.1\%), 15 patients of abnormal potassium level $(40.5 \%)$, and 16 patients of abnormal chloride level (43.2\%). There are 16 subjects with smoking history (40\%), 29 subjects of positive tuberculosis history (72.5\%), 6 subjects with positive tuberculosis family history (15\%), 30 subjects of pain as main problems $(75 \%), 5$ subjects of swelling or pus as main problems $(12.5 \%), 5$ subjects of extremities disability as main problems $(12.5 \%)$. Dominant location of infection is vertebrae $(95 \%)$ which are suffered by 38 subjects with thoracal as the main level of infection, suffered by 15 subjects $(50 \%)$. Other levels of infection are lumbal with 12 subjects $(40 \%)$, cervical with 3 subjects $(10 \%)$, and pelvis or thigh with 2 subjects $(5 \%)$.

Conclusion: From 40 subjects, bone and joint tuberculosis mostly suffered by elderly, male risks more than female. Most of hematology tests results were abnormal. Most subjects suffered abnormal C-reactive protein. Most subjects' hematology tests were BUN, creatinine serum, and electrolyte normal. Number of subjects with smoking habits was dominant. Most subjects were having tuberculosis history but negative family history. Most subjects complained about pain with vertebrae level thoracal as dominant location of infection.

* Correspondence: sjahjenny@gmail.com

JUXTA: Jurnal IImiah Mahasiswa Kedokteran Universitas Airlangga

p-ISSN: 1907-3623; e-ISSN: 2684-9453

DOI: $10.20473 /$ juxta.V11/12020.1-5

Open access under Creative Commons Attribution-ShareAlike 4.0 International License

(CC-BY-SA)
ARTICLE INFO

\author{
Article history: \\ Received 04 December 2019 \\ Received in revised form 14 \\ January 2020
}

Accepted 23 January 2020

\section{Keywords:}

Bone Tb,

Tuberculosis,

Clinical Profile,

Bone and Joint. 


\section{Introduction}

Bone and joint TB is a chronic disease with an everincreasing mortality rate in the last decade because it is a difficult infectious disease to treat. ${ }^{1}$ Indonesia is in the 9th of the highest estimated numbers of incident TB cases, ranks 7th out of 20 MDR-TB cases, and ranks out of 20 countries with the highest estimated TB numbers of incident cases among people living with $\mathrm{HIV}^{2}$ Globally, TB is still a major problem, in India there are $26 \%$ of TB cases. ${ }^{3}$ TB bone is not only a problem in developing countries but also in developed countries. This infection can attack any organ with $1-3 \%$ involvement of bone lesions. ${ }^{4}$

Of the total cases of extrapulmonary TB, $50 \%$ of cases were reported as cases of tuberculosis and joints. ${ }^{5}$ Cases of TB infection in the bones and joints are supported by immunodeficiency in young people with pain and swelling in the extremities. ${ }^{6}$ Children are also at high risk for TB infection as adults.

Based on inpatient data from Orthopaedics and Traumatology Department RSUD Dr. Soetomo, from 2015 to 2018 , there were 53 cases $(9.23 \%)$ of Bone TB. This study aims to determine the clinical profile of bone and joint TB which includes hematological examination results, main complaints, comorbidity, history of smoking patients, history of TB patients, family history of exposure to TB, dominant location of infection, and risk factors that can trigger bone TB infection.

\section{Methods}

This study was conducted by descriptive observational using secondary data from medical records of inpatients in RSUD Dr. Soetomo Surabaya starting from 2015-2018 and obtained 40 patients with bone TB.

\section{Results}

Distribution of Bone and Joint TB According to Age and Sex

Table 1. Distribution of cases according to age.

\begin{tabular}{cccc}
\hline Age Group & Age Range & $\begin{array}{c}\text { Frequency } \\
(\mathrm{n})\end{array}$ & $\begin{array}{c}\text { Percent } \\
(\%)\end{array}$ \\
\hline 1 & 0-10 years & 3 & 7.5 \\
2 & $11-20$ years & 1 & 2.5 \\
3 & $21-30$ years & 11 & 27.5 \\
4 & $31-40$ years & 10 & 25.0 \\
5 & $41-50$ years & 8 & 20.0 \\
6 & $51-60$ years & 5 & 12.5 \\
7 & 61-70 years & 2 & 5.0 \\
& Total & 40 & 100 \\
\hline
\end{tabular}

The average age group of bone TB patients based on the analysis results was 4.05 with a standard deviation of 1.501.

Table 2. Distribution of cases according to sex.

\begin{tabular}{ccc}
\hline & Frequency $(\mathrm{n})$ & Percent $(\%)$ \\
\hline Men & 22 & 55 \\
Women & 18 & 45 \\
& & \\
Total & 40 & 100 \\
\hline
\end{tabular}

Distribution by sex stated that there were 22 men and 18 women of a total of 40 inpatient bone and joint TB.

Distribution of bone and joint TB according to $\mathrm{Hb}$, leucocyte, thrombocyte, ESR, C-reactive protein, BUN, creatinine serum, and electrolyte

Table 3. Distribution of cases according to $\mathrm{Hb}$, leucocyte, thrombocyte, ESR, C-reactive protein, BUN, creatinine serum, and electrolyte.

\begin{tabular}{|c|c|c|}
\hline & $\begin{array}{l}\text { Frequency } \\
\text { (n) }\end{array}$ & $\begin{array}{c}\text { Percent } \\
(\%)\end{array}$ \\
\hline \multicolumn{3}{|l|}{$\mathrm{Hb}$} \\
\hline Normal & 11 & 27.5 \\
\hline Abnormal & 29 & 72.5 \\
\hline \multicolumn{3}{|l|}{ Leucocyte } \\
\hline Normal & 25 & 62.5 \\
\hline Abnormal & 15 & 37.5 \\
\hline \multicolumn{3}{|l|}{ Thrombocyte } \\
\hline Normal & 20 & 50.0 \\
\hline Abnormal & 20 & 50.0 \\
\hline \multicolumn{3}{|l|}{ ESR } \\
\hline Normal & 2 & 5.6 \\
\hline Abnormal & 34 & 94.4 \\
\hline \multicolumn{3}{|l|}{ C-reactive protein } \\
\hline Normal & 17 & 45.9 \\
\hline Abnormal & 20 & 54.1 \\
\hline \multicolumn{3}{|l|}{ BUN } \\
\hline Normal & 35 & 92.1 \\
\hline Abnormal & 3 & 7.9 \\
\hline \multicolumn{3}{|l|}{ Serum creatinine } \\
\hline Normal & 27 & 71.1 \\
\hline Abnormal & 11 & 28.9 \\
\hline \multicolumn{3}{|l|}{ Sodium } \\
\hline Normal & 24 & 64.9 \\
\hline Abnormal & 13 & 35.1 \\
\hline \multicolumn{3}{|l|}{ Potassium } \\
\hline Normal & 22 & 59.5 \\
\hline Abnormal & 15 & 40.5 \\
\hline \multicolumn{3}{|l|}{ Chloride } \\
\hline Normal & 21 & 56.8 \\
\hline Abnormal & 16 & 43.2 \\
\hline
\end{tabular}

Based on table 3, there were 29 patients $(72.5 \%)$ with abnormal $\mathrm{Hb}, 15$ patients $(37.5 \%)$ with abnormal leukocyte, 20 patients $(50 \%)$ with abnormal thrombocyte, 2 patients $(5.6 \%)$ with normal ESR values and 34 patients $(94.4 \%)$ with abnormal ESR values of a total of 36 patients who had ESR, 17 patients $(45.9 \%)$ with normal C-reactive protein, 20 patients $(20 \%)$ with abnormal $\mathrm{C}$-reactive protein and 3 patients did not have C-reactive protein, 3 patients $(7.9 \%)$ with abnormal BUN, 2 patients who did not have BUN, 11 patients $(28.9 \%)$ with abnormal creatinine serum, and 2 patients with no creatinine serum.

Based on electrolyte distribution which includes sodium, potassium, and chloride, there were 13 patients $(35.1 \%)$ with abnormal sodium, 15 patients $(40.5 \%)$ with abnormal potassium, 16 patients (43.2\%) with abnormal chlorides, and 3 patients with no electrolyte examination. 
Distribution of Bone and Joint TB According to history of smoking patients, history of TB patients, family history of exposure to TB, Main Complaints, Comorbid Diseases, and Dominant Locations of Infection

Table 4. Distribution of cases according to history of smoking patients, TB patients, family history of exposure to TB, Main Complaints, Co-morbid Diseases, and Dominant Locations of Infection.

\begin{tabular}{lcc}
\hline & $\begin{array}{c}\text { Frequency } \\
(\mathrm{n})\end{array}$ & $\begin{array}{c}\text { Percent } \\
(\%)\end{array}$ \\
\hline Smoking History & 24 & 60 \\
Nonsmoking & 16 & 40 \\
Smoking & & \\
\hline TB patients History & 11 & 27.5 \\
TB negative & 29 & 72.5 \\
TB positive & & \\
\hline Family history of TB & & \\
Infection & 34 & 85 \\
TB negative & 6 & 15 \\
TB positivie & & \\
\hline Main Complaint & 30 & 75 \\
Pain & 5 & 12.5 \\
Swelling or pus & 5 & 12.5 \\
Extremity disability & & \\
\hline Cold Abscess & 12 & 30.0 \\
Abscess positive & 28 & 70.0 \\
Abscess negative & & \\
\hline Comorbidity & 7 & 17,5 \\
Others diseases & 33 & 82.5 \\
No comorbidities & & \\
\hline Localization & 38 & 95.0 \\
Vertebra & 2 & 5.0 \\
Limb & 3 & 10.0 \\
\hline Vertebra Level & 12 & 50.0 \\
Cervical & & 40.0 \\
\hline Thorakal & & \\
Lumbal & & \\
\hline & & \\
\hline & & \\
\hline
\end{tabular}

There were 16 patients (40\%) who had history of smoking, 29 patients $(72.5 \%)$ who had history of positive TB, 6 patients (15\%) with positive family history of TB, 30 patients $(75 \%)$ with major complaints of pain, 5 patients $(12.5 \%)$ with the main complaint was a lump or pus, and 5 patients $(12.5 \%)$ with limb weakness. Abscesses occurred in 12 patients $(30 \%)$, and other diseases such as diabetes and asthma occurred in 7 patients (17.5\%). According to the location of infection, thoracal is the main attacked location $(50.0 \%)$ of bone TB infection.

\section{Discussion}

Descriptive Analysis Results of Bones and Joints TB According to Age and Sex

The most age group of bone and joint TB patients hospitalized at RSUD Dr. Soetomo Surabaya is $21-30$ years old. Distribution of bone TB often occurs in young immigrants (20-35 years) in Europe and one of the risk factors for osteoarticular TB is in line with increasing age and malnourished parents. ${ }^{7,8}$ There were 3 patients under 10 years old, 2 patients aged 3 years old and 1 patient aged 7 years old. Children have a high incidence of developing TB up to $40 \%$ after primary infection.

Children have more dangerous onset because it appears without obvious symptoms in most cases of extrapulmonary TB that is supported by low immunity in infants. Children and adolescents to be a high risk factor for the development of extrapulmonary TB. ${ }^{9}$

Bone and joint TB increased slightly in men with 22 cases and women with 18 cases of the overall cases. A study at Teerthanker Mahaveer Medical College, India, explained that osteoarticular TB increased slightly in male. ${ }^{10}$ This can be explained because there are many factors in the body and the environment that support the occurrence of Mycobacterium tuberculosis infection. The study at Xinxiang Medical College Hospital also explained that out of 180 cases, the number of male patients was higher (108 patients) compared to women (72 patients). ${ }^{1}$

Descriptive Analysis Results of Bones and Joints TB According to $\mathrm{Hb}$, Leucocyte, Thrombocyte, ESR, CReactive Protein, BUN, Creatinine Serum, and Electrolyte

There were 29 patients $(72.5 \%)$ with anemia, 15 patients $(37.5 \%)$ with abnormal leukocytes, 20 patients $(50 \%)$ with abnormal thrombocytes, 2 patients $(5.6 \%)$ with normal ESR, 34 patients $(94,4 \%)$ with abnormal ESR of a total of 36 patients, and 4 patients who did not have ESR. A study of an extrapulmonary TB patient from Eritrea, East Africa, had abnormal hematologic examination, such as anemia, leukocytosis, leukopenia, thrombocytosis, thrombocytopenia, and pancytopenia. ${ }^{11}$ Anemia, leukocytosis, thrombocytosis, and increased ESR describe the infection reaction of Mycobacterium tuberculosis and cause inflammation. In some cases of spinal TB, a marked increase in ESR is also followed by a normal leukocyte value. $^{12}$

ESR examination is one of the routine checks in cases of TB bones and joints. Although not specific, ESR examination is very important because atypical mycobacterium infections show normal ESR values. ${ }^{10}$ However, the normal ESR value accompanied by a negative skin test also does not exclude TB diagnosis. ${ }^{13}$

The number of patients with abnormal C-reactive protein values was slightly higher than patients with normal $\mathrm{C}$-reactive protein values from the overall cases. In accordance with the research conducted at Hasan Sadikin Hospital in Bandung, an increase in C-reactive protein values indicates the process of infection, inflammation, burns, and malignancy followed by leukocytosis. C-reactive protein is also used to detect bacterial infections, how acute or serious a disease is, detection of systemic inflammatory processes in the body. ${ }^{14}$

ESR and C-reactive protein are markers of acute phase reactions. However, C-reactive protein is more sensitive and can detect changes faster than ESR. C-reactive protein is a useful marker in the acute phase because it reacts quickly to the inflammatory process, both infections, autoimmune diseases, and tissue necrosis.

False positives and false negatives often occur in ESR measurements, because several factors such as kidney disease, female sex, and older age increase the ESR value. There are 2 situations where ESR examination is better than C-reactive protein, which is detecting low grade bone and joint infections and monitoring disease activity in SLE. ${ }^{15}$

There were more patients with normal BUN than patients with abnormal BUN. Patients with normal serum creatinine were also more likely than patients with abnormal serum creatinine. BUN and serum creatinine describe kidney function. This is not in accordance with a research which explains that one of the predisposing factors for osteoarticular TB is a renal dysfunction and renal failure. ${ }^{8}$

This study showed only parts of the patients who had abnormal electrolyte values with a total of 40 patients. 
Hyponatremia and hypercalcaemia are also found in some patients with abnormal electrolyte values which is in line with the research of Jonaidi Jafari at Baqiyatallah Hospital, Tehran, Iran which explains that hyponatremia and hypercalcemia are abnormalities that often occur in TBinfected patients. ${ }^{16}$

\section{Descriptive Analysis Results of Bones and Joints TB According to History of Smoking patients, history of TB patients, family history of exposure to TB, Main Complaints, Comorbid Diseases, and Dominant Locations of Infection}

Number of patients with smoking history is low (40\%) which is accordance with the study in a case of an immigrant from Haiti that smoking is also one of the risk factors for TB infection. ${ }^{17}$ Someone who smokes is also 3 times more at risk of TB infection than nonsmokers. ${ }^{3}$

Number of patients with history of TB infection was higher which were 29 patients $(72.5 \%)$ out of 40 patients. This result is in line with a study that showed TB infection and exposure to TB from surrounding people is one of key diagnoses. ${ }^{8}$ Patients with negative history of TB infection can be infected with TB when interacting with people who are infected with pulmonary TB when coughing, talking, or singing. ${ }^{18}$

This difference might occur because of the number of cases in this study is fewer or exposure via inhalation had no significant effect. However, the influence of TB exposure from the surrounding environment is reinforced by a study which stated that one of the key diagnoses of TB infection is the presence of TB exposure from the surrounding environment and history of TB infection. ${ }^{8}$ Extrapulmonary TB also occurs several years after exposure to surrounding people with TB infection supported by low immunity. ${ }^{19}$

The main complaints of pain $(75 \%)$ are more common than other complaints such as lumps or pus and weakness of the extremities. This result is in line with a study which explained that all patients from a total of 58 cases in 2010 in Taiwan had major complaints of pain, 50 patients accompanied by swelling, and 53 patients with neurological symptoms. ${ }^{7}$

Distribution of comorbidities includes abscesses in 12 patients $(30 \%)$, and 7 patients $(17.5 \%)$ with other comorbidities such as diabetes mellitus and asthma. In several cases of bone TB, paralegia can be a result of mechanical compression and abscess. ${ }^{12}$ In diabetic patients there is a disruption in the response of humoral and cellular immunity, such as deficits in c3, c4, c1 inhibitors, changes in response via tumor necrosis factor (TNF), interleukin (IL) -1 $\beta$, IL-2, IL-6, IL -8, and insulin growth factor (IGF) -2 thus supporting TB infection. ${ }^{8}$

Locations that are often infected are vertebrae with 38 patients $(95 \%)$, and 2 patients $(5 \%)$ with the location of limb infections. Of the 38 patients with infections in the vertebrae, thoracic levels were most often infected as many as 15 patients $(50 \%)$. These results are in accordance with a study which explained that out of 140 cases of osteoarticular tuberculosis (OT) in Naples in 1975-2004, 79 cases $(56.4 \%)$ occurred in the spine. ${ }^{20}$

Research conducted at Xinxiang Medical College Hospital also explained that of 180 cases, 135 cases were spinal TB and 45 cases of limb tuberculosis. ${ }^{1}$ The dominance of vertebrae levels is supported by a study with data from several countries, that predilection of TB bacillus infection in the vertebrae is due to large vascular supply and is a long bone growth plate. ${ }^{7}$

\section{Conclusion}

From 40 subjects, bone and joint tuberculosis mostly suffered by elderly, male risks more than female. Most of hematology tests results were abnormal. Most subjects suffered abnormal C-reactive protein. Most subjects' hematology tests were BUN, creatinine serum, and electrolyte normal. Number of subjects with smoking habits was dominant. Most subjects had tuberculosis history but negative family history. Most subjects complained about pain with vertebrae level thoracal as dominant location of infection.

\section{Acknowledgement}

1. The workers at Medical Records, RSUD Dr. Soetomo Surabaya.

2. Authors contributed in the discussion and interpretation of the results, and in the drafting and editing the manuscript.

\section{CONFLICT OF INTEREST}

The author stated there is no conflict of interest in this study.

\section{REFERENCES}

1. Yang L and Liu Z. Analysis and Therapeutic Schedule of the Postoperative Recurrence of Bone Tuberculosis. J Orthop Surg Res. 2013; 8: 47-.

2.Organization WH. Global Tuberculosis Report 2018. Geneva: World Health Organization, 2018.

3.Sharma SK and Mohan A. Tuberculosis: From an Incurable Scourge to a Curable Disease - Journey Over a Millennium. The Indian Journal of Medical Research. 2013; 137: 45593.

4.Arora $\mathrm{K}$ and Chaudhary $\mathrm{P}$. Tuberculosis of Talus Bone in Middle Aged Man - A Case Report. International Journal of Orthopaedic and Trauma Nursing. 2014; 18: 35-8.

5.Agrawal V, Patgaonkar PR and Nagariya SP. Tuberculosis of Spine. J Craniovertebr Junction Spine. 2010; 1: 74-85.

6. Hu S, Guo J, Ji T, Shen G and Kuang A. Multifocal Osteoarticular Tuberculosis of the Extremities in an Immunocompetent Young Man without Pulmonary Disease: A Case Report. Exp Ther Med. 2015; 9: 2299-302.

7.Pigrau-Serrallach $C$ and Rodríguez-Pardo D. Bone and Joint Tuberculosis. Eur Spine J. 2013; 22 Suppl 4: 556-66.

8.Moon M-S. Tuberculosis of Spine: Current Views in Diagnosis and Management. Asian Spine J. 2014; 8: 97111.

9.Kritsaneepaiboon S, Andres MM, Tatco VR, Lim CCQ and Concepcion NDP. Extrapulmonary Involvement in Pediatric Tuberculosis. Pediatric Radiology. 2017; 47: 1249-59.

10.N A, Ahmad F and Huda N. Osteoarticular Tuberculosis-A Three Years' Retrospective Study. J Clin Diagn Res. 2013; 7: 2189-92.

11.Alghamdi AA, Awan FS, Maniyar IH and Alghamdi NA. Unusual Manifestation of Extrapulmonary Tuberculosis. Case Reports in Medicine. 2013; 2013: 353798.

12.Garg RK and Somvanshi DS. Spinal Tuberculosis: A Review. J Spinal Cord Med. 2011; 34: 440-54.

13.Karakaplan M, Köroğlu M, Ergen E, Aslantürk O, Özdemir ZM and Ertem K. Isolated Tuberculosis of Capitate and Triquetrum. J Wrist Surg. 2017; 6: 70-3. 
14.Irawati, Melinda $\mathrm{H}$ and Idjradinata PS. Kesesuaian Nilai CReactive Protein dan Procalcitonin dalam Diagnosis Pneumonia Berat pada Anak. Sari Pediatri. 2010; 12: 78.

15. Harrison M. Erythrocyte Sedimentation Rate and CReactive Protein. Aust Prescr. 2015; 38: 93-4.

16.Jonaidi Jafari N, Izadi $M$, Sarrafzadeh F, Heidari $A$, Ranjbar R and Saburi A. Hyponatremia Due to Pulmonary Tuberculosis: Review of 200 Cases. Nephrourol Mon. 2013; 5: 687-91.
17.Inayat $F$, Jafar MS, Ali NS, Hussain $Q$ and Hurairah $A$. Enigma of Extrapulmonary Tuberculosis: Where Do We Stand? Cureus. 2017; 9: E1554.

18.Prevention CFDCA. How TB Spreads: (2016).

19.Loddenkemper $R$, Lipman $M$ and Zumla A. Clinical Aspects of Adult Tuberculosis. Cold Spring Harbor Perspectives in Medicine. 2015; 6: A017848.

20.Maricnda M, Cozzolino A, Attingenti P, Cozzolino F and Milano . Osteoarticular Tuberculosis in a Developed Country. The Journal of Infection. 2007; 54: 375-80. 